\title{
An attempt to assess the value of epidemiological structure of sexual networks in the detection of syphilis infection
}

\author{
Maria Soszka-Jakubowska, Małgorzata Janczyło-Jankowska, Adam Jakubowski \\ Department of Dermatology and Venereology, Medical University of Bialystok, Poland
}

Przegl Dermatol 2014, 101, 15-20 DOI: 10.5 | |4/dr.20|4.41067

KEY WORDS:

early syphilis, sexual networks, network of $k$-core type.

ADDRESS FOR CORRESPONDENCE: Maria Soszka-Jakubowska $\mathrm{MD}, \mathrm{PhD}$

Department of Dermatology and Venereology

Medical University of Bialystok

14 Żurawia St, 15-540 Bialystok, Poland

e-mail: adam.jakubowski.bstok@ wp.pl

\section{ABSTRACT}

Introduction. Sociometric studies based on the evaluation of structures forming interpersonal network earned widespread recognition in sexually transmitted diseases (STD) epidemiology.

Objective. The aim of this work is to assess the importance of epidemiological studies of infection sources, contacts and the network of connections created by them in the detection of early syphilis infections in the Bialystok province (1989-2010).

Material and methods. Material for the study was the documentation of 316 patients diagnosed with early syphilis and 265 registered contacts declared by them, observed and treated in STD clinics. Epidemiological assessment was based on the basic parameters. Social Network Analysis was based on parameters of Seidman $k$-core.

Results. Epidemiological studies showed that $67.4 \%$ of 316 patients with early syphilis reported registered contacts (index 0.83 ). 87.5\% of these contacts have been tested and in more than a half $(53 \%)$ of them early syphilis has been diagnosed. The remaining $16.8 \%$ of patients (with their consent) were subjected to prophylactic treatment, and the rest (after an appropriate time of control) were considered to be not infected. Thirty-three persons $(12.5 \%)$ could not be found. Social Network Analysis of 316 patients showed that as many as 176 $(53.7 \%)$ did not show any links in epidemiologic investigations. One hundred and twenty-two patients had 2-6 personal links without creating a k-core. Only in 1995, during a syphilis microepidemic (in town C), has a typical network of sexual relationships with a $k$-core consisting of 18 patients been revealed.

Conclusions. The results of the study indicate major shortcomings in the work of STD clinics in Podlaskie Province in the years 1999-2010. Analysis of the structure of sexual networks is a valuable method for enriching the methodology of epidemiological investigations in detecting sources of infection and their contacts, provided very detailed epidemiological investigations are performed and there is close cooperation with other STD clinics. Social Network Analysis of infection sources and their sexual contacts allows forecasting the morbidity, as well as selecting groups according to their sexual behavior, regions in which infections may appear and patients' social and ethnic group. 


\section{INTRODUCTION}

In addition to health education, screening programmes, therapy of patients and prophylactic treatment of their symptomless contacts, a fundamental element of the system of elimination of sexually transmitted diseases (STD) is the detection of sources of infection and contacts.

A useful tool which has been widely recognized in the epidemiology of STD are sociometric tests that assess structures of connection networks existing between people that form them. The method, which is suitable for investigating reactions which occur between individuals (microstructural network) or groups of people (macrostructural network) in the direct or indirect transmission of an aetiological agent of infection, makes it possible to assess the perception of the problem in greater detail, and take preventive measures. The process of creating structures of such a network can involve sociodemographic or epidemiological contexts, or risky sexual behaviours [1].

Studies analyzing networks of micro- and macrostructural relations use a variety of visual models. Figure 1 presents examples of network microstructures and their average number of partners (based on Potterat et al. [2]), and Seidman's k-core method [3] represented graphically in the studies by Friedman et al. [1] and Potterat et al. [2]. In both methods the network of macrostructural connections is formed by groups of people who are linked to one another either directly or indirectly, e.g. by sociodemographic or epidemiological contexts, or sexual behaviours.

The microstructural network assessment presented by Potterat et al. [2] comprises two levels, lower- and higher-order, depending on the number of people involved and their connectivity. Lower-order microstructures are formed by a single infected

Lower-order microstructures:

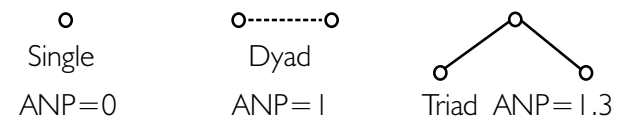

Higher-order microstructures:

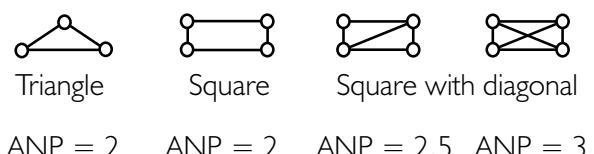

$A N P=2 \quad A N P=2 \quad A N P=2.5 \quad A N P=3$

The microstructures of the network and the number of their partners (ANP) by Potterat et al. [2] person and contacts specified by that person: two (a dyad in which each member is the other's sole partner, ANP-1) and three persons (a triad) connected in the form of an unclosed triangle. Higher-order microstructures are based on direct or indirect connections involving three or more partners functioning in closed systems which can be represented visually as a triangle, a square or a star.

In Seidman's network structure represented graphically in the study by Friedman et al. [1] the authors distinguish individual unconnected persons (designated in the figure by the letter " $c$ ") or two connected persons (designated by the letters " $a$ " and " $b$ ") who are not a part of the k-core. The latter type is characterized by a closed system of direct or indirect links between partners (where $k$-core represents a subset in which every component is connected to a certain minimum number $(k)$ of other components of the subset). Such a visual representation may include cases of peripheral endings of the large interconnected set (designated in the figure by the letters " $j$ " and " $k$ ") or cases such as the one marked with the letter " $\mathrm{i}$ ", where no 2-core connection is formed because there is a link to just one partner from the core system designated in the figure by the letter " $\mathrm{h}$ ".

Analyzing the two graphs, it is possible to identify both microstructure network levels also in Friedman's representation: cases marked as " $c$ ", " $i$ ", " $j$ " and " $k$ ", and the dyad " $a-b$ ", are a part of the lower-order level, whereas the " $\mathrm{d}-\mathrm{h}$ " system is accommodated within the higher-order level.

The methods of structural network analysis discussed above, which take into consideration diverse (sociodemographic, epidemiological and behavioural) contexts, have proven useful in accounting for problems associated with the transmission of pathogenic organisms causing STD - both viruses $[1,2,4$, 5] and bacteria [5-11].

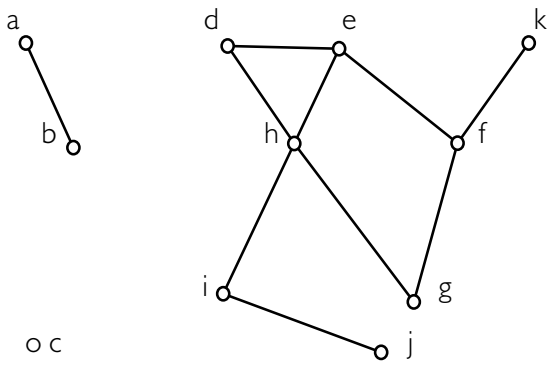

The social network analysis of $k$-core type according to Seidman by Friedman et al. [1]

Figure I. Diagrams of social network analysis of people with STDs 


\section{OBJECTIVE}

The aim of the study is to assess the epidemiological value of investigations into sources of infection and contacts, and structures of connection networks which they create, for the identification of early syphilis infections in an area corresponding to the former Białostockie province (1989-1999) and the current Podlaskie province (1999-2010).

\section{MATERIAL AND METHODS}

The study material comprised records available for a total of 316 patients with early syphilis and 265 of their named contacts that were followed up and treated at venereology clinics. The diagnosis of early syphilis was made on the basis of assays detecting Treponema pallidum in specimens harvested from pathological lesions, and serological tests (USR, VDRL, FTA-ABS, TPHA). The patients were divided into two groups. One consisted of a total of 162 individuals from the period 1989-1998 (Białostockie province), the other comprised 154 patients from the period 1999-2010 (Podlaskie province).

The epidemiological assessment of the study material was performed on the basis of a set of parameters including number and percentage of patients with early syphilis providing their named contacts, number and percentage of named contacts, number and percentage of examined contacts together with identified infections, and number and percentage of named contacts receiving prophylactic treatment.
The assessment of structures of connection networks included unconnected individuals, connected individuals without core formation, with core formation and functioning as end components of the core system.

\section{RESULTS}

Results of own studies are listed in Tables I and II, and in Figure 2. As shown in Table I, out of 316 patients with early syphilis named contacts were given by 213 patients $(67.4 \%)$. Other patients either stated their contacts were casual or denied them altogether. Out of 265 named contacts (index 0.83), a total of 232 $(87.5 \%)$ were examined, and 123 (ca. 53\%) were found to have symptoms of early syphilis. Prophylactic treatment was given to 39 contacts (16.8\%) (with their consent) who were negative in the first clinical and serological tests. Following a standard observation period syphilis infection was ruled out in the remaining 70 cases (ca. 32\%).

In the period 1989-1998, named contacts were provided by $71.6 \%$ of patients - index 0.98 (in 19992010 the percentage was $62.9 \%$, index 0.68 ), of which health examinations were given to $91.8 \%$ (for comparison, in 1999-2010 it was $81.1 \%$ ) and early syphilis was detected in ca. $46 \%$ of cases (in 1999-2010 - in ca. $68 \%$ ). Prophylactic treatment was administered to nearly $20 \%$ of contacts that were negative in the first test (in 1999-2010 - 12.5\%). Approximately 34\% of negative named contacts were considered infection-

Table I. Epidemiological analysis of 316 patients with early syphilis in the years 1989-20 I0

\begin{tabular}{|c|c|c|c|c|c|c|c|c|c|c|c|c|c|c|c|}
\hline \multirow{3}{*}{ Years } & \multirow{3}{*}{$\begin{array}{c}\text { Number of } \\
\text { patients with } \\
\text { early syphilis }\end{array}$} & \multirow{2}{*}{\multicolumn{2}{|c|}{$\begin{array}{c}\text { Patients } \\
\text { notifying } \\
\text { name contacts }\end{array}$}} & \multicolumn{12}{|c|}{ Name contacts } \\
\hline & & & & \multicolumn{2}{|c|}{ Notified } & \multicolumn{2}{|c|}{ Investigated } & \multicolumn{2}{|c|}{ Infected } & \multicolumn{2}{|c|}{ Negative } & \multicolumn{2}{|c|}{$\begin{array}{l}\text { Proph. } \\
\text { therapy }\end{array}$} & \multicolumn{2}{|c|}{$\begin{array}{l}\text { Non-inve- } \\
\text { stigated }\end{array}$} \\
\hline & & $n$ & $\%$ & $n$ & Rate & $n$ & $\%$ & $n$ & $\%$ & $n$ & $\%$ & $n$ & $\%$ & $n$ & $\%$ \\
\hline 1989-1998 & 162 & 116 & 71.6 & 159 & 0.98 & 146 & 91.8 & 67 & 45.8 & 50 & 34.2 & 29 & 19.8 & 13 & 8.2 \\
\hline |999-2010 & 154 & 97 & 62.9 & 106 & 0.68 & 86 & 81.1 & 56 & 65.1 & 20 & 23.2 & 10 & 11.6 & 20 & 18.9 \\
\hline |989-20|0 & 316 & 313 & 67.4 & 265 & 0.83 & 232 & 87.5 & 123 & 53.1 & 70 & 30.2 & 39 & 16.8 & 33 & 12.5 \\
\hline
\end{tabular}

Table II. The social network analysis of patients with early syphilis in the years 1989-20 I0

\begin{tabular}{|c|c|c|c|c|c|c|c|c|c|c|c|c|c|c|c|}
\hline \multirow{3}{*}{ Years } & \multirow{3}{*}{$\begin{array}{l}\text { Number of } \\
\text { patients }\end{array}$} & \multirow{2}{*}{\multicolumn{2}{|c|}{$\begin{array}{c}\text { Unconnected } \\
\text { persons }\end{array}$}} & \multicolumn{8}{|c|}{ Persons connected without $k$-core } & \multirow{2}{*}{\multicolumn{2}{|c|}{$\begin{array}{l}\text { Connected } \\
\text { with } k \text {-core }\end{array}$}} & \multirow{2}{*}{\multicolumn{2}{|c|}{$\begin{array}{l}\text { Peripheral } \\
\text { ends inter- } \\
\text { connected } \\
\text { component }\end{array}$}} \\
\hline & & & & \multicolumn{2}{|c|}{2 persons } & \multicolumn{2}{|c|}{3 persons } & \multicolumn{2}{|c|}{4 persons } & \multicolumn{2}{|c|}{6 persons } & & & & \\
\hline & & $\bar{n}$ & $\%$ & $n$ & $\%$ & $n$ & $\%$ & $n$ & $\%$ & $n$ & $\%$ & $n$ & $\%$ & $n$ & $\%$ \\
\hline |989-1998 & 162 & 86 & 53.1 & 40 & 24.7 & 6 & 3.7 & & & 12 & 7.4 & 14 & 8.6 & 4 & 2.5 \\
\hline 1999-2010 & 154 & 90 & 58.4 & 52 & 33.8 & & & 12 & 7.8 & & & & & & \\
\hline |989-2010 & 316 & 176 & 55.7 & 92 & 29.1 & 6 & 1.9 & 12 & 3.8 & 12 & 3.8 & 14 & 4.4 & 4 & 1.3 \\
\hline
\end{tabular}




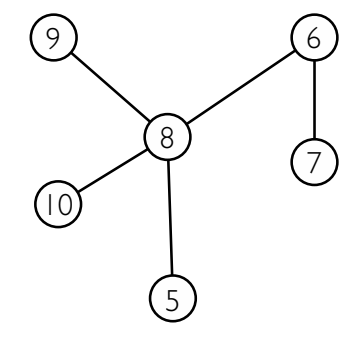

Year 1989 - microepidemic in $Ł$
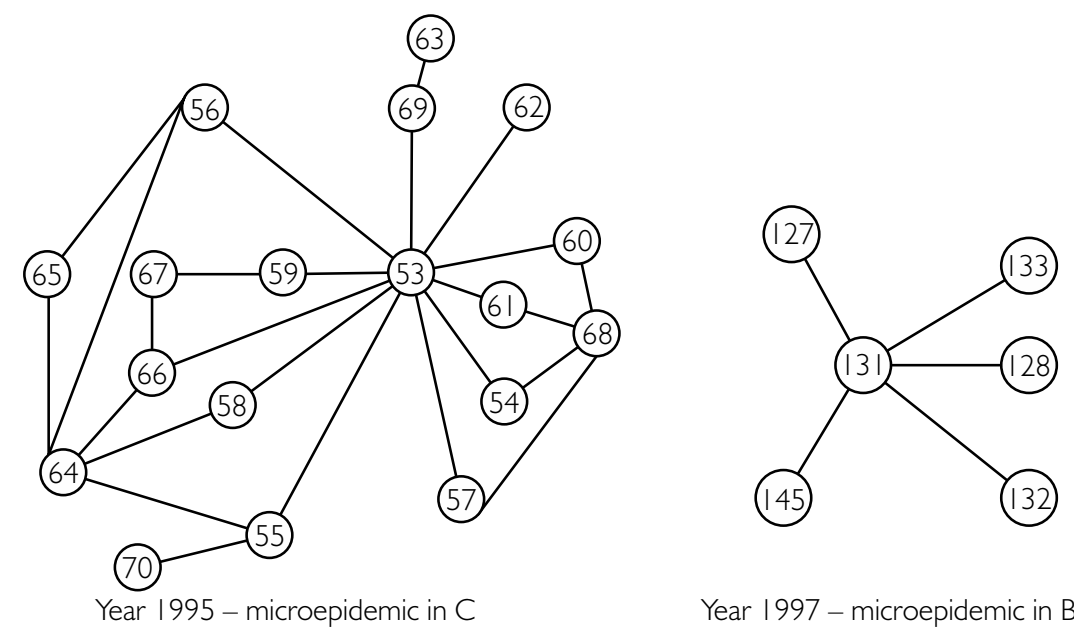

Year 1997 - microepidemic in B

Figure 2. The network links patients with early syphilis in the province of Bialystok in the years 1989, 1995 and 1997

free (in 1999-2010 - ca. 23\%). Approximately $8.2 \%$ of named contacts could not be found (in 1999-2010 ca. $19 \%)$.

Table II shows the network of connections in groups of early syphilis patients in 1989-2010. Out of 316 early syphilis patients 176 individuals (55.7\%) did not report any mutual connections in epidemiological investigations. The majority stated they had casual sexual encounters, often with partners living abroad, or denied having any contacts. In the remaining cases the most common connection patterns were those involving 2 people (29.1\% of study patients), 4 and 6 people $(3.8 \%$ each) and 3 people $(1.9 \%)$. With the exception of 1995, no cases were found to involve networks of connections forming k-cores. Only in 1995, based on thorough epidemiological investigations, it was possible to demonstrate a typical network of connections between a total of 18 early syphilis patients (Fig. 2). The majority of them were inhabitants of the village designated as $C$, situated on the border with Belarus. The source of infection was a 32-yearold unemployed single woman, a resident of the village, designated with the number 53. She was most likely infected by the patient no. 61, a 37-year-old railway worker from the village $\mathrm{H}$ who was diagnosed with relapsing secondary syphilis. He reported having a chance sexual encounter with a partner from Belarus several months before. The patient no. 53 (relapsing secondary syphilis) specified seven contacts who were then diagnosed with early syphilis (no. 54 and nos. 56-61) and a patient who proved negative in initial clinical and serological tests, but consented to the administration of prophylactic treatment. The patient no. 53 was reported as a source of infection by another 4 partners who were diagnosed with early syphilis (nos. 55, 62, 66 and 69). Further epidemio- logical investigations of contacts named by the latter four patients led to the detection of another 6 cases of early syphilis (nos. 63-65, 67, 68 and 70). Overall, the microepidemic involved observations of 38 people. Early syphilis was diagnosed in 18 cases (16 inhabitants of $C$, one of $€$ and one of $B$ - patients no. 60 and no. 70) and therapy was introduced. Further seven patients received prophylactic treatment. In 10 cases, based on clinical and serological observation, syphilis infection was excluded. The remaining three contacts could not be found.

As shown in Figure 2, 14 out of 18 patients created a closed network of indirectly connected persons forming two large cores (nos. 53-60-68-57 and nos. 53-56-65-64-55) joined together by the patient no. 53 . Within the two large cores, eight smaller core systems - each composed of between 3 and 6 individuals - can be identified (nos. 56-64-65; 53-60-68-61; 53-61-68-54; 53-54-68-57; 53-59-67-66; 53-66-6458 ; 53-58-64-55 and nos. 53-56-64-66-67-59). On the periphery of the extensive network consisting of 14 people there are four patients (nos. 62, 63, 69 and 70) as peripheral ends of the large interconnected component.

In the period under analysis, there were another two microepidemics of syphilis in the former Białostockie province: in $€$ in 1989, and in B in 1997 (Fig. 2).

Ten cases of early syphilis were identified during the microepidemic in $€$, however only six of them made up a network without core-type connections. The source of infection was a 39-year-old unemployed woman (patient no. 8) who named eight contacts. Out of that number, four people were diagnosed with early syphilis (patients nos. 5, 6, 9 and 10). Further two received prophylactic treatment and another two were confirmed as free from infection. 
Patient no. 6 infected his wife (patient no. 7). In the remaining four cases of early syphilis detected in $€$ there were no demonstrable epidemiological connections with the six-patient group discussed above.

In 1997, there were 33 cases of early syphilis in the Białostockie province, however only in 6 cases it was possible to demonstrate a connection not forming a core system. The source of infection was a 43-yearold unemployed homeless woman who spent the nights on the premises of the railway station in B (patient no. 131). The woman reported 6 sexual contacts. Five of her partners were infected (patient nos. 127, 132 and 133 residing in $B$, patient no. 128 from $C$, and patient no. 145 from BP). One partner was not found.

In 1999-2010, a total of 154 cases of early syphilis were analyzed in the area of the newly established Podlaskie province. The annual incidence varied between 2 and 22 cases. There was, however, no identifiable network of connections forming $k$-cores.

\section{DISCUSSION}

A review of available literature indicates high epidemiological efficacy of the method of investigating contacts among sexual partners with early syphilis. Special attention is drawn to named contacts provided by treated patients because immediate initiation of therapy makes it possible to break the chain of infection relatively quickly and reduce incidence rates. The index of named contacts determined for the period under analysis (0.83) was markedly lower than indices specified by Stapiński [12] for Poland as a whole in the 1970s (ranging from 1.0 to 1.34). It was also lower than indices quoted in US studies from the turn of the $21^{\text {st }}$ century [13-15] which varied from 1.38 to 6.25 . The percentage of examined contacts in the own study discussed here was approximately $90 \%$ and corresponded to results obtained in the above-mentioned Polish studies (from $60 \%$ to $>90 \%$ ) and in one US study (from $20 \%$ to $90 \%$ ). The index of detected cases of early syphilis among named contacts in the current study was higher (over $50 \%$ ) than Polish data cited by Stapiński [12] (from $25 \%$ to $45 \%$ ) and US studies (from $12 \%$ to $27 \%$ ).

A more in-depth review of incidence parameters of early syphilis in the Podlaskie province clearly demonstrates shortcomings in the epidemiological activity of the outpatient clinic in 1999-2010, i.e. after the administration and healthcare reforms. The reform abolished methodology and organization departments of Province Dermatology and Venereology Outpatient Clinics which used to coordinate activities undertaken by the epidemiology division with respect to STD. The responsibilities were transferred to local dermatology facilities which, however, do not cooperate closely. The reorganization, coupled with the inadequacy of epidemiological activities carried out by frequently inexperienced medical practitioners, resulted in a reduction of the number of named and examined contacts by nearly $10 \%$ compared to data available for the former Białostockie province (1989-1998). The situation entailed a drop of the index of contacts from 0.98 to 0.68 , and a nearly $20 \%$ increase in the number of infected individuals among reported contacts. What the above data demonstrate is that the period from contact identification to medical examination is now too long, and the rule of providing prophylactic treatment to reported contacts is not followed (in 1999-2006 prophylactic therapy was administered to only 10 such contacts, and in 2007 the procedure was withdrawn). There was also an increase in the percentage of reported but unexamined contacts (from ca. $8 \%$ to nearly 19\%), and decreases in epidemiology index (from 0.57 to 0.20 ) and examination effectiveness index (from 0.41 to 0.36 ).

Assessment of the structure of networks formed by infected individuals and their sexual partners (sexual networks) occupies a central role among methods which enhance the value of contact investigation aimed at detecting sexually transmitted diseases of bacterial and viral origin, and preventing their propagation. Having analyzed links between 316 patients included in our study, we were only able to identify a typical $k$-core network comprising 18 patients during the microepidemic which occurred in C in 1995, which may result from the greater number of early syphilis cases (40 patients), local microepidemics and meticulous epidemiological investigation. The importance of reliable data on sexual contacts, and difficulties involved in gathering such data, are discussed by Frost [17], who emphasizes their significance for a precise analysis of the structure of the connection network. Doherty et al. [18] draw attention to the fact that regions characterized by stable low incidence rates and high numbers of cases tend to have networks that are small and dendritic, suggesting the endemic nature of epidemics. This was precisely the epidemiological situation observed in the former Białostockie province in 1995.

Literature reports underscore that analyzing the structure of networks of connections existing between sources of infection and their sexual contacts makes it possible to forecast incidence patterns $[7,8$, $16,17]$ and phases of epidemics $[4,16,19]$, and to isolate groups depending on behaviours [9], social and ethnic background and regions $[9,18,19]$. The problems are extensively discussed by Doherty et al. [20].

\section{CONCLUSIONS}

Results of own studies presented above demonstrate marked shortcomings in epidemiological ac- 
tivities conducted by dermatology (venereology) outpatient clinics operating in the Podlaskie province in 1999-2010, manifested as a reduction of basic epidemiological indices used for assessing the incidence of early syphilis. The alarming tendency may be potentially caused by a lower degree of interest in venereology problems, poor cooperation between medical practitioners in outpatient clinics and lack of a coordinating body following the healthcare reform of 1999 which phased out methodology and organization departments of Province Dermatology Outpatient Clinics.

Analysis of the structure of sexual networks is a valuable method complementing the methodology of epidemiological investigations aimed at the detection of infection sources and their contacts. However, as stressed in available literature, the success of the method is conditional on the availability of detailed epidemiological data and close cooperation with other venereology centres. Analyzing the structure of networks of connections existing between sources of infection and their sexual contacts makes it possible to forecast future incidence patterns and isolate groups depending on behaviours, social and ethnic background, and determine potential regions in which the disease may break out.

\section{References}

1. Friedman S.R., Neaigus A., Jose B., Curtis R., Goldstein M., Ildefolso G., et al.: Sociometric risk networks and risk for HIV infection. Am J Public Health 1997, 87, 1289 1296.

2. Potterat J., Rothenberg R, Muth S.: Network structural dynamics and infectious disease propa-gation. Int J STD AIDS 1999, 10, 182-185.

3. Seidman S.B.: Network structure and minimum degree. Soc Networks 1983, 267-287.

4. Potterat J., Phillips-Plumer L., Muth S., Rothenberg R.B. Woodhouse D.E., Maldonado-Long T.S., et al: Risk network structure in early epidemic phase HIV transmission in the Colorado Springs. Sex Transm Dis 2002, 78 (suppl 1), 159-163.

5. Soszka-Jakubowska M.: Znaczenie wykrywania kontaktów w zwalczaniu zakażenia HIV, kiły i rzeżączki. Rozprawa doktorska, Białystok, 2006. Archiwum Biblioteki UMB w Białymstoku.

6. Rothenberg R., Sterk C., Toomey K.E., Potterat J.J., Johnson D., Schrader M., et al.: Using social network and ethnographic tools to evaluate syphilis transmission. Sex Transm Dis 1998, 25, 154-160.

7. Engelgau M.M., Woernle C.H., Rolfs R.T., Greenspan J.R., O' cain M., Gorsky R.D., et al.: Control of epidemic early syphilis: the results of an intervention compaign using social networks. Sex Transm Dis 1995, 22, 203-209.

8. Rothenberg R.B., Kimbrough L., Lewis-Hardy R., Health B., Wiliams O.C., Tambe P., et al.: Social network methods for endemic foci of syphilis: a pilot project. Sex Transm Dis 2000, 27, 92-98.

9. Rosenberg D., Moseley K., Kahn R., Kissinger P., Rice J., Kendall C., et al.: Networks of person with syphilis and at risk for syphilis in Louisiana: evidence of core transmitters. Sex Transm Dis 1999, 26, 108-114.
10. Ghani A.C., Swinton J., Garnett G.P.: The role of sexual partnership networks in the epidemiology of gonorrhea. Sex Transm Dis 1997, 24, 45-56.

11. Jolly A.M., Muth S.Q., Wyllie J.L., Potterat J.J.: Sexual networks and sexually transmitted infectious, a tale of two cities. J Urban Health 2001, 78, 433-445.

12. Stapiński A.: Zwalczanie kiły i rzeżączki w Polsce, PZWL, Warszawa, 1979.

13. Paterman T.A., Toomey K.E., Dicker L.A., Zaidi A.A., Wroten J.E., Cardina J., et al.: Partner notification for syphilis: a randomized,controlled trial of the approaches. Sex Transm Dis 1997, 24, 511-518.

14. Kissinger P.J., Nicolai L.M., Magnus M., Farley T.A., Maher J.E., Richardson-Alston G., et al.: Partner notification for HIV and syphilis: effects on sexual bahaviours and relationship stability. Sex Transm Dis 2003, 30, 75-82.

15. Kohl K.S., Farley T.A., Ewell J., Scioneaux J.: Usefulness of partner notification for syphilis control. Sex Transm Dis 1999, 26, 201-207.

16. Potterat J.J., Muth S.Q., Rothenberg J.R., ZimmermanRogers H., Green D.L., Taylor J.E., et al.: Sexual network structure as an indicator of epidemic phase. Sex Transm Dis 2002, 78, 152-158

17. Frost S.D.: Using sexual affiliation networks to describe the sexual structure of population. Sex Transm Dis 2007, 83, 37-42.

18. Doherty I.A., Serre M.L., Gesing D., Adimora A.A., Muth S.Q., Leone P.A., et al.: Sexual networks, surveillance, and geographical space during syphilis outbreaks in rural North Carolina. Epidemiology 2012, 23, 845-851.

19. Ward H.: Prevention strategies for sexually transmitted infections: importance of sexual network structure and epidemic phase. Sex Transm Dis 2007, 83, 43-49.

20. Doherty I.A., Padian N.S., Marlow C., Aral S.O.: Determinants and consequences of sexual networks as they affect the spread of sexually transmitted infections. J Infect Dis 2005, 191, 42-54.

Received: 10 I 2014

Accepted: 28 I 2014 